\title{
Sagu de mandioca no Brasil: um paralelo entre a pesquisa de mercado e a rotulagem
}

\section{de alimentos}

Cassava sago in Brazil: a parallel between market research and food labeling

Sagú de mandioca en Brasil: un paralelo entre la investigación de mercado y el etiquetado de alimentos

Recebido: 07/09/2021 | Revisado: 15/09/2021 | Aceito: 17/09/2021 | Publicado: 19/09/2021

\author{
Anna Carolina Alves Gomes da Silva-e-Silva \\ ORCID: https://orcid.org/0000-0002-8926-8411 \\ Universidade Federal do Estado do Rio de Janeiro, Brasil \\ E-mail: annacarolina.alvesgomes@yahoo.com.br \\ Anderson Junger Teodoro \\ ORCID: https://orcid.org/0000-0002-0949-9528 \\ Universidade Federal do Estado do Rio de Janeiro, Brasil \\ E-mail: atteodoro@gmail.com \\ Isabelle Santana \\ ORCID: https://orcid.org/0000-0001-7402-2139 \\ Universidade do Estado do Rio de Janeiro, Brasil \\ E-mail: isabellesantana@gmail.com
}

\begin{abstract}
Resumo
A presença da mandioca e de seus derivados na alimentação brasileira é expressiva, exceto para o sagu de mandioca. Diante deste cenário, faltam estudos que revelem a extensão desse alimento no mercado brasileiro. O objetivo deste trabalho foi elucidar tal panorama a partir de uma pesquisa de mercado considerando a rotulagem e informações de publicidade, centrando-se na oferta on-line de sagus de mandioca no comércio brasileiro. As categorias sagu seco, mistura para sagu e sagu pronto para consumo foram avaliadas considerando: região de venda e preço, parâmetros de identidade e qualidade, lista de ingredientes, conteúdo líquido, tabela nutricional, porção e medidas caseiras, informações sobre glúten, lactose e alérgenos alimentares, embalagem e sites de venda ou oficiais. Foram considerados 81 produtos nacionais, sendo 75,3\% (n=61) sagus secos, 19,7\% $(n=16)$ misturas para sagu e 5,0\% $(n=4)$ sagus prontos para consumo. Os sagus secos apresentaram inadequações em todas as categorias. As misturas para sagus foram adequadas nos parâmetros porção e medidas caseiras, informação sobre glúten e lactose. Os sagus prontos para consumo obtiveram erros sistemáticos por serem da mesma marca. Logo, foi possível aprofundar o panorama de produtos disponíveis e preços praticados, sendo o primeiro estudo realizado para o mercado brasileiro. Mesmo com uma quantidade relevante de sagus de mandioca no mercado, diversas marcas apresentam inadequação na rotulagem, o que comprova a necessidade de reformulação. Por fim, entende-se que os canais virtuais de comunicação podem ser mais utilizados para atrair a atenção dos consumidores para estes produtos, desde que haja linguagem técnica apropriada.
\end{abstract}

Palavras-chave: Sagu de mandioca; Rotulagem; Manihot esculenta Crantz.

\begin{abstract}
The presence of cassava and its derivatives in Brazilian food is expressive, except for cassava sago. Given this scenario, there is a lack of studies that reveal the extension of this food in the Brazilian market. The aim of this work was to elucidate this scenario from market research considering the labeling and advertising information, focusing on the online offer of cassava sago in the Brazilian market. The categories "dry sago", "mixture for preparing sago desserts" and "ready-to-eat sago desserts" were evaluated considering region of sale and price, quality and identity parameters, list of ingredients, liquid content, nutritional table, portion and homemade measures, information on gluten, lactose and food allergens, packaging and sales or official websites. Eighty-one (81) national products were evaluated, consisting of $75.3 \%(n=61)$ dry sago, $19.7 \%(n=16)$ mixtures for sago desserts and $5.0 \%(n=4)$ ready-to-eat sago desserts. Dry sago showed inadequacies in all categories. The mixtures for preparing sago were adequate regarding labeling of portion and household measures, and information on gluten and lactose. Ready-to-eat sago presented systematic errors for being of the same brand. Therefore, it was possible to deepen the panorama of available products and prices, being the first study carried out for the Brazilian market. Even with a relevant amount of available cassava sago, several brands have inadequate labeling, which proves the need for reformulation. Finally, it is understood that virtual communication channels can be more used to attract the attention of consumers to these products, as long as there is appropriate technical language.
\end{abstract}

Keywords: Tapioca pearl; Food labeling; Manihot esculenta Crantz. 


\begin{abstract}
Resumen
La presencia de la yuca y sus derivados en la comida brasileña es expresiva, a excepción del sagú de la yuca. Ante este escenario, faltan estudios que revelen la extensión de este alimento en el mercado brasileño. El objetivo de este trabajo es dilucidar este escenario a partir de una investigación de mercado considerando el etiquetado y la información publicitaria, centrándose en la oferta en línea de yuca sagús en el comercio brasileño. Se evaluaron las categorías de sagú seco, mezcla para sagú y sagú listo para consumir considerando: región de venta y precio, parámetros de identidad y calidad, lista de ingredientes, contenido líquido, tabla nutricional, ración y medidas caseras, información sobre gluten, lactosa y alérgenos, envases y sitios de ventas o oficiales. Se consideraron 81 productos, de los cuales 75,3\% $(n=61)$ fueron sagú seco, 19,7\% $(n=16)$ fueron mezclas para sagú y 5,0\% $(n=4)$ fueron sagú listo para consumir nacionalmente. Los sagús secos mostraron deficiencias en todas las categorías. Las mezclas para sagús fueron adecuadas en la porción de parámetros y medidas domésticas, información sobre gluten y lactosa. Los sagús listos para comer tenían errores sistemáticos por ser de la misma marca. Por lo tanto, fue posible profundizar el panorama de productos disponibles y precios, siendo el primer estudio realizado para el mercado brasileño. Incluso con una cantidad importante de yuca sagus en el mercado, varias marcas tienen un etiquetado inadecuado, lo que demuestra la necesidad de reformulación. Finalmente, se entiende que los canales de comunicación virtual se pueden utilizar más para atraer la atención de los consumidores hacia estos productos, siempre que exista un lenguaje técnico adecuado.
\end{abstract}

Palabras clave: Sagu; Etiquetado de alimentos; Manihot esculenta Crantz.

\title{
1. Introdução
}

O sagu de mandioca, também denominado como tapioca pérola ou sagu artificial, é um produto alimentício esférico, opaco e de coloração branca, quando seco e cru. É preparado a partir da fécula de mandioca umedecida e moldada em esferas, resultando em um produto similar ao sagu verdadeiro, o qual é extraído de palmeiras específicas (Metroxylon spp.). Para o consumo nacional são caracterizados dois tipos, 1 e 2, de acordo com características físico-químicas e, assim como o sagu verdadeiro, o sagu de mandioca é constituído principalmente de amido. Quando cozido, adquire aspecto translúcido, aumento de volume (>2,5 vezes) e obtém textura gelatinosa, semelhante a ovas de peixe (Brasil, 2005; Alves \& Santana, 2019; Serviço Brasileiro de Respostas Técnicas - SBRT, 2007; Lorenzen, 1912).

A mandioca (Manihot esculenta Crantz) é uma das matérias-primas para a produção comercial de sagu no Brasil, o que caracteriza uma vantagem por ser uma raiz amilácea nativa deste país (Instrução Normativa n. 23, 2005; Alves \& Santana, 2019). De acordo com a Organização das Nações Unidas para a Alimentação e a Agricultura - FAO, a raiz de mandioca está entre os 10 cultivos mais produtivos em nível mundial (299 milhões de toneladas em 2020), sendo o Brasil o quinto maior produtor, contribuindo com 17 milhões de toneladas (Food and Agriculture Organization of the United, 2021).

Além do caráter econômico, é notável a presença cultural da mandioca e de seus derivados na alimentação brasileira, como a mandioca de mesa, as farinhas e as gomas (Alves \& Santana, 2019; Cascudo, 2011). No entanto, o cenário para consumo de sagu é regionalizado e predomina como ingrediente de sobremesas, sendo tanto o produto seco e cru, quanto as sobremesas, denominados "sagu". O sagu de vinho tinto faz parte da culinária típica da região sul, tendo como principal expoente o estado do Rio Grande do Sul. Também é possível encontrar receitas com leite de coco pelo nordeste brasileiro, com menos expressividade (Peccini, 2008; Alves \& Santana, 2019).

Ainda assim, no principal levantamento nacional sobre consumo alimentar do brasileiro, a Pesquisa de Orçamentos Familiares - POF, foi considerado o sagu. Contudo, este foi incluído no grupo de doces à base de leite e sem expor a frequência de consumo na população. Por outro lado, são expostas informações sobre a mandioca de mesa, farinha de mandioca e farofa nas edições voltadas para o perfil alimentar, mantendo o caráter cultural em evidência (Instituto Brasileiro de Geografia e Estatísticas, 2004, 2011, 2020).

Sob outra perspectiva, é notável perceber a diversidade de consumo do sagu, verdadeiro ou de mandioca, internacionalmente, principalmente na Ásia e na Oceania. Sua presença está em receitas tradicionais doces e salgadas, elaboradas com diferentes métodos de cocção, como ebulição, fritura, estourados e assados. A variedade de aplicações 
culinárias desse alimento se reflete em produtos comerciais como o "bubble tea", e viabiliza o desenvolvimento de receitas para atender públicos com necessidades nutricionais específicas quanto à consistência da dieta (ex: branda, pastosa), restrição de componentes específicos (ex. glúten, proteína) ou mesmo que busquem criar alternativas para outros alimentos, como a versão de "caviar vegetal" (Alves \& Santana, 2019).

No Brasil, os parâmetros de identidade e qualidade de sagu de mandioca são definidos pela RDC 23/2005, os quais devem ser obrigatoriamente indicados na rotulagem. Para o consumidor, é uma forma de acessar informações técnicas que retratam a qualidade do produto, sem indução ao erro ou equívoco. Tendo em vista a acompanhar as transformações do mercado, faz-se necessário reformular as legislações que visam trazer mais autonomia e segurança ao consumidor, influenciando positivamente na decisão de compra e consumo (Instrução Normativa, 2005 e 2020; Resolução do Diretório Colegiado, 2002 e 2020; Marins, Araújo \& Jacob, 2014). Para tal, a indicação quantitativa e/ou gráfica de certos componentes como alérgenos alimentares, lactose e açúcares adicionados, têm sido regulamentados em normas recentes, visto que podem ser necessariamente restritos na alimentação de alguns consumidores (Lei n. 10.674, 2003; Resolução do Diretório Colegiado, 2015, 2017a e 2017b, 2020; Instrução Normativa, 2020).

Os canais de comunicação das empresas também são formas de apresentar diferenciais para o consumidor. Nesse formato, sites de divulgação podem complementar os atributos destacados na embalagem. Pelo fato de a alimentação saudável estar cada vez mais em evidência como estratégia de preservar a saúde, os produtores de alimentos atendem à necessidade de tornar as informações mais atraentes, tanto nas embalagens quanto nos canais de comunicação (Goodman, 2003; Machado, Santos, Albinati \& Santos, 2006; Ministério da Saúde, 2014; David \& Guivant, 2020).

Diante deste cenário, ainda faltam estudos que revelem a presença e a extensão dos produtos sagu de mandioca no mercado brasileiro. O objetivo deste trabalho é elucidar tal panorama a partir de uma pesquisa de mercado atualizada que considere a rotulagem desses produtos, bem como dados de divulgação pelas empresas.

\section{Metodologia}

A pesquisa de mercado foi centrada na oferta de sagus de mandioca disponíveis no comércio brasileiro, divididos em três categorias: sagu seco, mistura para preparo de sobremesa à base de sagu (composta por sagu seco e pó contendo açúcar, polpa de fruta e aditivos) e sagu pronto para consumo. A busca foi realizada nas seguintes etapas: busca de marcas de sagu de mandioca comercial e produtos alimentícios elaborados com sagu através de um site oficiais das marcas de sagu, bem como sites de buscas (Google $\left.{ }^{\circledR}\right)$ com as palavras-chave 'sagu de mandioca', 'sagu' e, quando necessário 'sagu [nome da marca]'; tabulação e análise das informações levantadas sobre rotulagem nutricional e destaques visuais da embalagem.

As regiões de venda foram identificadas por dois formatos. No primeiro formato, foi considerada a abrangência local no estado do Rio de Janeiro, compreendendo os produtos comercializados no estado do Rio de Janeiro por geolocalização automática dos sites. No segundo formato, a localização de venda foi definida por região de entrega (estados ou bairros) em nível nacional disponível nos sites.

Foram analisadas as informações contidas no painel principal das embalagens (a parte da rotulagem onde se apresenta, de forma mais relevante, a denominação de venda e marca ou o logotipo, caso existam) de acordo com a RDC 429/2020; informações virtualmente disponibilizadas nos sites oficiais das marcas consideradas nessa pesquisa e/ou por contato via serviço de atendimento ao consumidor no período de junho de 2020 a maio de 2021.

Foi realizada uma amostragem não-probabilística por conveniência, uma vez que foram utilizados os dados disponíveis on-line (Estrela, 2018; Pereira, Shitsuka, Parreira \& Shitsuka, 2018).

Para tal avaliação, foi elaborado um roteiro técnico referente aos critérios de rotulagem dos alimentos com base nas 
legislações brasileiras vigentes, especificadas no Quadro 1.

Quadro 1. Critérios e itens referentes ao roteiro de avaliação da rotulagem de alimentos.

\begin{tabular}{|c|c|}
\hline Legislação referente & Critérios e informações consideradas \\
\hline $\begin{array}{l}\text { IN } 23 \text {, de } 15 \text { de dezembro de } 2005 \text {. } \\
\text { Aprova o regulamento técnico de identidade e qualidade } \\
\text { dos produtos amiláceos derivados da raiz de mandioca. }\end{array}$ & $\begin{array}{l}\text { Presença de Grupo, Subgrupo, Tipo, Denominação de } \\
\text { venda específica. }\end{array}$ \\
\hline $\begin{array}{l}\text { RDC } \mathrm{n}^{\circ} 259, \mathrm{DE} 20 \text { DE SETEMBRO DE } 2002 . \\
\text { Aprova o Regulamento Técnico sobre Rotulagem de } \\
\text { Alimentos Embalados. }\end{array}$ & $\begin{array}{l}\text { Presença de denominação de venda, lista de ingredientes, } \\
\text { conteúdos líquidos, instruções do preparo do alimento, } \\
\text { quando necessário. }\end{array}$ \\
\hline $\begin{array}{l}\mathrm{RDC} \mathrm{n}^{\circ} 429 \text {, DE } 8 \text { DE OUTUBRO DE } 2020 . \\
\text { Dispõe sobre a rotulagem nutricional dos alimentos } \\
\text { embalados. }\end{array}$ & Tabela de informação nutricional \\
\hline $\begin{array}{l}\text { IN n }{ }^{\circ} 75 \text {, DE } 8 \text { DE OUTUBRO DE } 2020 . \\
\text { Estabelece os requisitos técnicos para declaração da } \\
\text { rotulagem nutricional nos alimentos embalados. }\end{array}$ & $\begin{array}{l}\text { Tamanho das porções de alimentos e referência de } \\
\text { medidas caseiras. }\end{array}$ \\
\hline $\begin{array}{l}\text { Lei } n^{\circ} 10.674 \text {, DE } 16 \text { DE MAIO DE } 2003 \text {. } \\
\text { Obriga a que os produtos alimentícios comercializados } \\
\text { informem sobre a presença de glúten, como medida } \\
\text { preventiva e de controle da doença celíaca. }\end{array}$ & Contém/não contém glúten \\
\hline $\begin{array}{l}\text { RDC n }{ }^{\circ} 135 \text {, de } 8 \text { de fevereiro de } 2017 \text {. } \\
\text { Altera a Portaria SVS/MS n }{ }^{\circ} 29 \text {, de } 13 \text { de janeiro de } 1998 \text {, } \\
\text { que aprova o regulamento técnico referente a alimentos } \\
\text { para fins especiais, para dispor sobre os alimentos para } \\
\text { dietas com restrição de lactose. } \\
\text { RDC n }{ }^{\circ} 136 \text {, de } 8 \text { de fevereiro de } 2017 \text {. } \\
\text { Estabelece os requisitos para declaração obrigatória da } \\
\text { presença de lactose nos rótulos dos alimentos. }\end{array}$ & Contém/não contém lactose \\
\hline $\begin{array}{l}\text { RDC N }{ }^{\circ} 26, \text { DE } 2 \text { DE JULHO DE } 2015 . \\
\text { Dispõe sobre os requisitos para rotulagem obrigatória dos } \\
\text { principais alimentos que causam alergias alimentares. }\end{array}$ & Presença de ingredientes alergênicos \\
\hline
\end{tabular}

Fonte: Autores (2021).

Para avaliar as informações de publicidade presente nos sites oficiais da marca, foi elaborada uma listagem com os conteúdos apresentados nos sites e no painel principal das embalagens comercializadas.

Foi calculada a média dos preços de venda (em reais por $\mathrm{kg}$ ) considerando as ofertas on-line de lojas varejistas com vendas físicas e/ou de delivery no período de fevereiro a maio de 2021.

Referente aos elementos de comunicação visual das embalagens, foram analisadas a presença de imagens dos ingredientes ou receitas prontas; informações de logotipo e mascotes que remetessem à marca; presença de figuras relacionadas a comidas ou festividades; e informações de diferenciação do produto quanto à origem (ex., selos, afetividade, tradição).

Os itens e critérios avaliados foram categorizados como: "adequado", quando os dados apresentados atendiam ao requisito exigido; "inadequado", quando o rótulo não atendia ao requisito exigido; "não avaliado", quando não foi possível obter a informação; "não se aplica", quando o requisito não se enquadrou ao produto avaliado.

Como critérios de exclusão, foram desconsiderados os sagus de mandioca a granel sem marcas, produtos sem sites oficiais ou com embalagens ilegíveis disponíveis na internet.

A análise dos dados foi realizada no software Microsoft Excel ${ }^{\circledR}$ por meio de estatística descritiva e os resultados foram apresentados segundo suas frequências absolutas, percentuais, médias, valores máximos e mínimos a partir das categorias analisadas. 


\section{Resultados e Discussão}

A partir da pesquisa de mercado, foram encontrados 105 produtos alimentícios com denominação de venda "sagu" ou "sagu de mandioca". Seguindo os critérios de exclusão foram desconsiderados 24 produtos, correspondendo a 20 sagus secos, 3 misturas para preparo de sagu (sagu seco e mistura de ingredientes secos para preparo da sobremesa) e 1 sagu pronto para consumo (sobremesa de sagu cozido com outros ingredientes). Logo, foram considerados 81 produtos alimentícios, sendo $75,3 \%(\mathrm{n}=61)$ na versão seca, $19,7 \%(\mathrm{n}=16)$ como mistura para sagu nos sabores uva, morango, vinho e framboesa, e $5,0 \%$ $(\mathrm{n}=4)$ na versão de sagu pronto para consumo, nos sabores café, creme, vinho e chocolate.

\subsection{Regiões de venda, pesos líquidos dos produtos, e preço de venda}

Foram encontradas marcas de sagus secos em 11 estados (Roraima, Pernambuco, Distrito Federal, Goiás, Mato Grosso do Sul, Rio de Janeiro, Minas Gerais, São Paulo, Espírito Santo, Paraná, Santa Catarina e Rio Grande do Sul), os quais abrangeram as cinco regiões brasileiras. O Sul e o Sudeste foram as regiões com a maior presença de sagus secos, abrangendo respectivamente $51 \%$ e $45 \%$ das marcas, seguidas pelas regiões Centro-Oeste (6\%), Norte (4\%) e Nordeste (3\%). Similar ao sagu seco, as misturas para sagu predominaram nas regiões Sudeste e Sul, com respectivamente 93,3\% e 80\% das marcas, seguidas pelo Centro-Oeste (13,3\%). Não foram encontradas misturas para sagus nas regiões Norte e Nordeste. Os sagus prontos para consumo foram encontrados em somente 1 local de venda on-line, no estado de São Paulo - região Sudeste.

Nas versões de sagu seco, o peso líquido de venda variou de $250 \mathrm{~g}$ a $25 \mathrm{~kg}$, sendo 88,3\% das marcas vendidas em

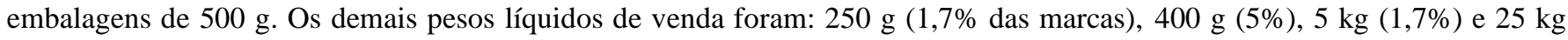
$(3,3 \%)$. Nas versões mistura para sagu, foram encontradas embalagens com peso líquido de 250 g para todos os produtos, consistindo em $100 \mathrm{~g}$ de sagu seco e $150 \mathrm{~g}$ de preparado para sagu. As versões de sagu pronto para consumo foram encontradas nas versões $70 \mathrm{~g}, 140 \mathrm{~g}, 750 \mathrm{~g}$ e $1,2 \mathrm{~kg}$ no site oficial.

Considerando os preços de venda dos sagus secos, a média de preço nacional está em $\mathrm{R} \$ 12,52 / \mathrm{kg}$, com valor médio de $\mathrm{R} \$ 6,29$ por pacote nas diversas gramaturas encontradas, tendo a faixa de preço entre $\mathrm{R} \$ 2,99$ (contendo $250 \mathrm{~g}$ ) e $\mathrm{R} \$ 110,00$ (contendo $25 \mathrm{~kg}$ ). A média nacional das misturas para sagus foi de $\mathrm{R} \$ 27,21 / \mathrm{kg}$, com valor médio de $\mathrm{R} \$ 6,80 /$ pacote e faixa de preço entre $\mathrm{R} \$ 4,11$ e $\mathrm{R} \$ 9,49$. As versões prontas para consumo encontradas foram de uma única marca, vendidas em embalagens de 140 g. Porém, só foi possível encontrar 1 preço de venda no sabor creme (R\$ 3,49 em São Paulo/ Região Sudeste), o qual correspondeu a $\mathrm{R} \$ 24,9 / \mathrm{kg}$.

\subsection{Rotulagem nutricional}

A rotulagem nutricional é toda declaração destinada a informar ao consumidor as propriedades nutricionais do alimento, compreendendo a tabela de informação nutricional, a rotulagem nutricional frontal e as alegações nutricionais. Deve também ser de fácil visualização e de difícil remoção, assegurando informações corretas, claras, precisas, ostensivas e em língua nativa, cumprindo com as exigências previstas na legislação específica em vigor (Resolução do Diretório Colegiado n. 259, 2002).

Na Tabela 1 são expressas a denominação de venda adequada, assim como as inadequações para este critério, em produtos de sagu comercializados no Brasil. 
Tabela 1. Denominação de venda em sagus secos, misturas para sagus e sagus prontos para consumo disponíveis para comercialização no Brasil (81 produtos).

\begin{tabular}{|c|c|c|c|c|c|c|}
\hline \multirow[t]{2}{*}{ Itens } & \multicolumn{2}{|c|}{ Sagus Secos } & \multicolumn{2}{|c|}{ Misturas para sagu } & \multicolumn{2}{|c|}{ Sagus prontos para consumo } \\
\hline & $\mathrm{n}$ & $\%$ & $\mathrm{n}$ & $\%$ & $\mathrm{n}$ & $\%$ \\
\hline $\begin{array}{l}\text { Denominação de venda adequada } \\
\text { Tapioca pérola ou Sagú artificial }\end{array}$ & 0 & 0 & 0 & 0 & 0 & 0 \\
\hline Inadequações & 61 & 100 & 16 & 100 & 4 & 100 \\
\hline $\operatorname{Sag}(\mathbf{u}) \mathrm{u}$ & 44 & 19,7 & 9 & 56,3 & - & - \\
\hline Sag(ú)u de Mandioca & 12 & 1,6 & - & - & - & - \\
\hline Com ambos: Sagu e Sagu de mandioca & 1 & 1,6 & - & - & - & - \\
\hline Sagu para sobremesa & 1 & 1,6 & - & - & - & - \\
\hline Sagu de mandioca Premium & 1 & 1,6 & - & - & - & - \\
\hline Sagu Pérola & 1 & 1,6 & - & - & - & - \\
\hline Saguzinho Pérola & 1 & 72,1 & - & - & - & - \\
\hline Sag(ú)u sabor & - & - & 7 & 43,7 & - & - \\
\hline $\operatorname{Sag}(u ́) \mathrm{u}+[$ nome da marca] & - & - & - & - & 4 & 0 \\
\hline
\end{tabular}

$\mathrm{n}=$ Frequência absoluta encontrada; $\%=$ Percentual referente. De acordo com a Instrução Normativa n $^{\circ} 23$ de 15 de dezembro de 2005 do Ministério da Agricultura, Pecuária e Abastecimento/MAPA, não faz parte do regulamento técnico de identidade e qualidade do sagu de mandioca outras denominações de venda além de "Tapioca pérola" e "sagú artificial" ou termos de qualidade, como premium. Portanto, nenhum produto se adequou ao estipulado na legislação vigente.

Fonte: Autores (2021).

De acordo com a Tabela 1, nenhum dos produtos nas três versões apresentou a denominação de venda como indicado na legislação vigente (Instrução Normativa n.23, 2005). Apesar da Resolução Normativa n. 259/2002 permitir a denominação de venda consagrada, quando a empresa optar por esta forma de apresentação, faz-se necessário constar informações que não induzam o consumidor ao engano sobre a natureza e/ou condições próprias do alimento.

Referente às informações de peso líquido, todos os produtos estiveram adequados, disponibilizando a gramatura no painel principal ou nos canais de divulgação, oficiais e/ou de venda, como mencionado previamente.

Visto que o sagu original é derivado de palmeiras-sagu (Metroxylon spp.), diferente da versão artificial comercializada no Brasil, é importante destacar esta diferença na embalagem. Um ponto de equívoco pode ser a existência de uma primeira resolução, outrora revogada. A Comissão Nacional de Normas e Padrões para Alimentos n.12/1978 determinava a necessidade de informar o nome do vegetal de origem quando o produto não for originário de espécies de palmeiras-sagu, porém, na legislação vigente (Instrução Normativa n. 23/2005) essa obrigatoriedade foi revogada e determinou-se o uso dos nomes Tapioca pérola ou Sagú artificial. Todos os sagus encontrados são à base de mandioca, mesmo que somente 22,9\% (n=14) dos produtos tenham declarado no painel principal.

Nas Tabelas 2, 3 e 4 estão expostas as denominações adequadas e inadequações encontradas para Grupo, Subgrupo e Tipo, as quais são aplicáveis, segundo a legislação (Instrução Normativa n.23/2005), para sagus secos e misturas para sagu, excluindo-se a categoria de sagus prontos para consumo. 
Tabela 2. Perfil de Denominação de Grupo em sagus secos e misturas para sagus disponíveis para comercialização no Brasil.

\begin{tabular}{|c|c|c|c|c|}
\hline \multirow[t]{2}{*}{ Itens } & \multicolumn{2}{|c|}{ Sagus Secos } & \multicolumn{2}{|c|}{ Misturas para sagu } \\
\hline & $\mathrm{n}$ & $\%$ & $\mathrm{n}$ & $\%$ \\
\hline $\begin{array}{l}\text { Denominação de grupo adequada } \\
\text { Grupo II - Tapioca }\end{array}$ & 30 & 49,2 & 14 & 87,5 \\
\hline Inadequações & 31 & $\mathbf{5 0 , 8}$ & 2 & 16,5 \\
\hline Grupo Tapioca & 15 & 24,6 & - & - \\
\hline Grupo 2 Tapioca & 1 & 1,6 & - & - \\
\hline Grupo Sagu & 1 & 1,6 & - & - \\
\hline Grupo II & 1 & 1,6 & - & - \\
\hline Grupo 2 & - & - & 2 & 16,5 \\
\hline Sem grupo no painel frontal ou Site & 13 & 21,3 & - & - \\
\hline
\end{tabular}

$\mathrm{n}=$ Frequência absoluta encontrada; \% = Percentual referente; esta categoria não se aplica para as versões "sagus prontos para consumo". De acordo com a Instrução Normativa $n^{\circ} 23$ de 15 de dezembro de 2005 do Ministério da Agricultura, Pecuária e Abastecimento/MAPA, os grupos são obrigatoriamente determinados por algarismos romanos, sendo um parâmetro de enquadramento para qualidade referente à tecnologia de fabricação.

Fonte: Autores (2021).

Tabela 3. Perfil de Denominação de Subgrupo em sagus secos e misturas para sagus disponíveis para comercialização no Brasil.

\begin{tabular}{|c|c|c|c|c|}
\hline \multirow[t]{2}{*}{ Itens } & \multicolumn{2}{|c|}{ Sagus Secos } & \multicolumn{2}{|c|}{ Misturas para sagu } \\
\hline & $\mathrm{n}$ & $\%$ & $\mathrm{n}$ & $\%$ \\
\hline $\begin{array}{l}\text { Denominação de sugrupo adequada } \\
\text { Pérola ou Sagú Artificial }\end{array}$ & 34 & $\mathbf{5 5 , 7}$ & 9 & 56,3 \\
\hline Inadequações & 27 & $\mathbf{4 4 , 3}$ & 7 & 43,7 \\
\hline Sagu artificial (sem indicar "subgrupo") & 2 & 3,3 & - & - \\
\hline Sagu artificial pérola & 1 & 1,6 & - & - \\
\hline Subgrupo Artificial & 1 & 1,6 & - & - \\
\hline Pérola (somente) & - & - & 7 & 43,7 \\
\hline Classe $^{*}$ & $\underline{14}$ & $\underline{23}$ & - & - \\
\hline Classe pérola & $\overline{7}$ & $\overline{11,5}$ & - & - \\
\hline Classe granulada & 1 & 1,6 & - & - \\
\hline Classe sagu & 3 & 4,9 & - & - \\
\hline Classe sagu artificial & 2 & 3,3 & - & - \\
\hline Classe artificial & 1 & 1,6 & - & - \\
\hline Sem subgrupo & 9 & 14,8 & - & - \\
\hline
\end{tabular}

$\mathrm{n}=$ Frequência absoluta encontrada; \% = Percentual referente; esta categoria não se aplica para as versões "sagus prontos para consumo". De acordo com a Instrução Normativa $n^{\circ} 23$ de 15 de dezembro de 2005 do Ministério da Agricultura, Pecuária e Abastecimento/MAPA, os tipos são obrigatoriamente determinados por algarismos indo-arábicos, ambos sendo parâmetros de enquadramento para qualidade referente à tecnologia de fabricação. Ainda, não faz parte do regulamento técnico de identidade e qualidade do sagu artificial de mandioca a classe do produto, configurando uma inadequação legal a sua presença nesse tipo de produto.

Fonte: Autores (2021). 
Tabela 4. Perfil de Denominação de Tipo em sagus secos e misturas para sagus disponíveis para comercialização no Brasil.

\begin{tabular}{|c|c|c|c|c|c|}
\hline \multirow[t]{2}{*}{ Itens } & & \multicolumn{2}{|c|}{ Sagus Secos } & \multicolumn{2}{|c|}{ Misturas para sagu } \\
\hline & & $\mathrm{n}$ & $\%$ & $\mathrm{n}$ & $\%$ \\
\hline \multirow[t]{3}{*}{ Denominação de tipo adequada* } & & 49 & 80,3 & 16 & 100 \\
\hline & Tipo 1 & 46 & 75,4 & 16 & 100 \\
\hline & Tipo 2 & 3 & 4,9 & - & - \\
\hline \multirow[t]{3}{*}{ Inadequações } & & 12 & 19,7 & 7 & 43,7 \\
\hline & Tipo I & 1 & 1,6 & - & - \\
\hline & Sem tipo & 11 & 18,1 & - & - \\
\hline
\end{tabular}

$\mathrm{n}=$ Frequência absoluta encontrada; \% = Percentual referente; esta categoria não se aplica para as versões "sagus prontos para consumo". De acordo com a Instrução Normativa $n^{\circ} 23$ de 15 de dezembro de 2005 do Ministério da Agricultura, Pecuária e Abastecimento/MAPA, o regulamento técnico de identidade e qualidade do sagu de mandioca possibilita o uso "fora de tipo" nos sagus de mandioca que apresentem, em base úmida, umidade acima de $15 \%$ ou teor de cinzas superior a $0,5 \%$. Nesta pesquisa de mercado não foram encontrados produtos com a denominação "fora de tipo".

Fonte: Autores (2021).

Analisando as Tabelas 2, 3 e 4 é possível avaliar que a informação sobre Grupo foi inadequada na maioria dos sagus $\operatorname{secos}(50,8 \%)$ e adequada nas misturas para sagu (87,5\%), apresentando equívocos sobre uso de numeração arábica ou falta de numeração, denominação de origem no local errado ou ausência de grupo, tanto no painel principal como nos canais de comunicação ou venda. Mesmo com inadequações, em 16 sagus secos (26,2\%) foi possível informar que o sagu era um produto categorizado como "tapioca", ou seja, informando sua origem ao consumidor. Não houve inadequação nas misturas para sagu por ausência de grupo.

Por outro lado, as informações de subgrupo (Tabela 3) nos produtos de sagu seco apresentaram 9 variações de inadequações, abrangendo $44,3 \%$ e sendo metade deles pela presença do termo "Classe", exigida somente para farinha de mandioca com a Instrução Normativa n. 52/2011. Dessa forma, uma vez que na legislação vigente específica para produtos amiláceos da mandioca não é mencionada essa categoria, não há possibilidade técnica desse termo. Por isso, deve ser um ponto de alerta para as empresas. Ao considerar as misturas para sagu, os resultados foram similares ao encontrado nos produtos de sagu seco. Duas marcas distintas informaram o subgrupo somente com "Pérola", que nesse sentido tem alusão ao formato do produto e não ao subgrupo, como determina a legislação (Instrução Normativa n.23, 2005).

Com relação ao Tipo, nos sagus secos a inadequação foi similar à categoria subgrupo, abrangendo $44,3 \%$ dos produtos selecionados. Vale destacar que 75,4\% enquadraram-se no tipo 1, alegando ter qualidade superior ao categorizar seu parâmetro físico-químico de teor de cinzas totais abaixo de 0,2\% em $100 \mathrm{~g}$ de produto (Instrução Normativa n.23, 2005). As misturas para sagu não apresentaram inadequações, e todos os produtos foram rotulados como tipo 1. A diferença de tipo é importante para o tempo de preparo e durabilidade das receitas com hidratação e cozimento em líquidos, já que sagus do tipo 1 conseguem tolerar mudanças por mais tempo sem perder o formato esférico característico (Alves \& Santana, 2019).

Os dados de denominação de porção e medidas caseiras, e inadequações encontradas para estes aspectos de rotulagem, estão demonstrados na Tabela 5, em sagus secos e misturas para sagus, e na Tabela 6, em sagus prontos para consumo. 
Tabela 5. Perfil de Denominação de Porção e Medidas Caseiras em sagus secos e misturas para sagus disponíveis para comercialização no Brasil.

\begin{tabular}{|c|c|c|c|c|}
\hline \multirow[t]{2}{*}{ Itens } & \multicolumn{2}{|c|}{ Sagus Secos } & \multicolumn{2}{|c|}{ Misturas para sagu } \\
\hline & $\mathrm{n}$ & $\%$ & $\mathrm{n}$ & $\%$ \\
\hline $\begin{array}{r}\text { Denominação de Porção com Medida caseira adequada } \\
\text { Porção de } 30 \text { gramas em Colheres de sopa }\end{array}$ & 18 & 29,5 & 7 & 43,7 \\
\hline Inadequações & 43 & $\mathbf{7 0 , 5}$ & 9 & 52,3 \\
\hline Porção 30 g sem Medida Caseira & 1 & 1,6 & - & - \\
\hline Porção $20 \mathrm{~g}$ em Colher de Sopa & 3 & 4,9 & 3 & $18,7 \%$ \\
\hline Porção $50 \mathrm{~g}$ em Colher de Sopa & 1 & 1,6 & - & - \\
\hline Porção 50 g em xícara & 2 & 3,3 & - & - \\
\hline Porção 60 g em xícara & 1 & 1,6 & - & - \\
\hline Não apresentam Tabela nutricional & 35 & 57,4 & 6 & $37,5 \%$ \\
\hline
\end{tabular}

$\mathrm{n}=$ Frequência absoluta encontrada; $\%=$ Percentual referente. Foram expostas somente as inadequações encontradas por essa pesquisa. De acordo com a Resolução do Diretório Colegiado n429 de 08 de outubro de 2020 da Agência Nacional de Vigilância Sanitária/ANVISA, a porção de um alimento é "necessária para preparar uma porção do produto pronto para o consumo" previamente definido por lei e a medida caseira é a "forma de quantificação da porção do alimento, por meio de utensílios, unidades ou outras formas comumente usadas pelo consumidor para mensurar os alimentos", sendo complementares ao consumidor.

Fonte: Autores (2021).

Tabela 6. Perfil de Denominação de Porção e Medidas Caseiras em sagus prontos para consumo disponíveis para comercialização no Brasil.

\begin{tabular}{|c|c|c|}
\hline \multirow[t]{2}{*}{ Itens } & \multicolumn{2}{|c|}{ Sagus prontos para consumo } \\
\hline & $\mathrm{n}$ & $\%$ \\
\hline $\begin{array}{l}\text { Denominação de Porção com Medida caseira adequada } \\
\text { Porção de } 100 \text { gramas em fração de pote }\end{array}$ & 0 & $0 \%$ \\
\hline Porção 100 g sem Medida Caseira & 4 & $100 \%$ \\
\hline
\end{tabular}

$\mathrm{n}=$ Frequência absoluta encontrada; \% = Percentual referente. De acordo com a Resolução do Diretório Colegiado nº 429 de 08 de outubro de 2020 da Agência Nacional de Vigilância Sanitária/ANVISA, a porção declarada de um alimento embalado individualmente deve corresponder à quantidade total do produto contido na embalagem. Nesse caso, os produtos continham $140 \mathrm{~g}$ de produto por embalagem, estando inadequados à legislação vigente.

Fonte: Autores (2021).

A tabela de informação nutricional é um item essencial da rotulagem para diversos produtos alimentícios. De acordo com a Resolução da Diretoria Colegiada n. 359/2003 e n. 429/2020, fica estabelecido que a porção determinada e a medida caseira correspondente devem ser adotadas pelos fabricantes na elaboração da tabela de informação nutricional de seus produtos alimentícios, buscando padronização e fácil compreensão pelo consumidor. No caso dos sagus de mandioca, essas informações são obrigatórias e vinculadas ao início da tabela nutricional, padronizada em porção de 30 gramas e medidas caseiras em colheres de sopa (Instrução Normativa n. 75, 2020).

Considera-se medida caseira como a "forma de quantificação da porção do alimento, por meio de utensílios, unidades ou outras formas comumente usadas pelo consumidor para mensurar os alimentos". A porção é a "quantidade de alimento utilizada como referência para fins de rotulagem nutricional" (Resolução do Diretório Colegiado n.429/2020). Considerando a Tabela 5, 29,5\% dos sagus secos e 47,3\% das misturas para sagu adequaram-se por completo às indicações regulatórias.

Considerando os sagus prontos para consumo apresentados na Tabela 6, a inadequação dos sagus prontos relacionada a esse critério foi a ausência de medida caseira, visto que a legislação vigente orienta a porção de 100 gramas ou mililitros para produtos da categoria prontos para consumo (Resolução do Diretório Colegiado n. 429/2020; Instrução Normativa n. 75/2020). 
Destaca-se que o erro se tornou sistemático por todos os produtos serem da mesma marca.

Para a versão de sagu seco, a porção apresentada teve uma variação entre os valores $20 \mathrm{~g}$ e $60 \mathrm{~g}$. Ainda assim, não houve uma padronização nas medidas caseiras, variando de 1 colher de sopa a 1/2 xícara de chá, até mesmo em porções de quantidades iguais. Desse modo, uma variação sem proporcionalidade descaracteriza a medida caseira indicada, podendo descumprir a clareza de informações e invalidar a própria tabela. Por outro lado, a versão mistura para sagu teve padronização de medidas caseiras na porção de 30 gramas $(47,3 \%)$ mesmo entre marcas concorrentes, correspondendo a 2 colheres de sopa. Ainda assim, ocorreram 18,7\% de inadequações na porção indicada.

Outro item imprescindível à rotulagem de alimentos é a lista de ingredientes. Em produtos mistos com 2 ou mais componentes, é determinado que a lista de ingredientes seja organizada em ordem quantitativamente decrescente (Resolução do Diretório Colegiado n.259/2002). Por conta de o sagu de mandioca seco produzido nacionalmente conter apenas 1 ingrediente, a presença da lista é facultativa. Ainda assim, 3 produtos apresentaram a lista de ingredientes com mandioca, fécula de mandioca ou amido de mandioca nos sites oficiais.

Em contrapartida, a lista de ingredientes é item obrigatório nas versões mistura para sagu e pronto para consumo. Além disso, 62,5\% das misturas para sagu $(\mathrm{n}=10)$ apresentaram a lista de ingredientes no site oficial da empresa, em todas contendo o açúcar como primeiro ingrediente. Todavia, em 37,5\% (n=6) dos produtos não há informações de ingredientes que os compõem.

De fato, há uma subutilização do potencial de comunicação com o consumidor direto, impedindo que estes possam compará-los a outros produtos ou mesmo conferir a existência de ingredientes de interesse. Mesmo assim, destaca-se que a declaração de presença de corantes artificiais esteve ausente no painel principal de 2 misturas para sagus (12,5\%) entre as 16 encontradas, ambos da mesma marca, não indicando a presença de aromatizantes artificiais no painel principal, contradizendo a própria lista de ingredientes e em desacordo com a legislação vigente (Decreto-lei n. 986, 1969; Informe Técnico n. 26, 2007).

Considerando o mesmo critério para as versões prontos para consumo, todos os produtos informaram a lista de ingredientes no site oficial da marca, o que possibilita o consumidor a comparar seu produto com os demais.

$\mathrm{Na}$ Tabela 7 são informados o perfil de adequações e inadequações dos componentes presentes na Tabela de Informação Nutricional em sagus secos, misturas para sagus e sagus prontos para consumo. 
Tabela 7. Perfil de Teores Nutricionais em sagus secos, misturas para sagus e sagus prontos para consumo disponíveis para comercialização no Brasil.

\begin{tabular}{|c|c|c|c|c|c|c|}
\hline \multirow[t]{2}{*}{ Itens } & \multicolumn{2}{|c|}{ Sagus Secos } & \multicolumn{2}{|c|}{ Misturas para sagu } & \multicolumn{2}{|c|}{$\begin{array}{l}\text { Sagus prontos } \\
\text { para consumo }\end{array}$} \\
\hline & $\mathrm{n}$ & $\%$ & $\mathrm{n}$ & $\%$ & $\mathrm{n}$ & $\%$ \\
\hline$\frac{\text { Presença de valor energético }(\mathbf{k c a l})}{\text { Presença adequada }}$ & 26 & 42,6 & 10 & 62,5 & 4 & 100 \\
\hline Ausência de valor energético & 35 & $\mathbf{5 7 , 4}$ & 6 & 37,5 & - & - \\
\hline$\frac{\text { Carboidratos }(\mathbf{g})}{\text { Presença adequada de arredondamento }}$ & 26 & 42,6 & 10 & 62,5 & 4 & 100 \\
\hline $\begin{array}{l}\text { Inadequações } \\
\text { Ausência de teor de carboidratos (g) }\end{array}$ & 55 & 57,4 & 6 & 37,5 & - & - \\
\hline$\frac{\text { Proteínas }(\mathbf{g})}{\text { Presença adequada de arredondamento }}$ & 1 & 1,6 & - & - & 4 & 100 \\
\hline Valor zero & 23 & 37,7 & - & - & - & - \\
\hline Inadequações $\quad$ Ausência de teor de proteínas (g) & 37 & 60,6 & - & - & - & - \\
\hline$\frac{\text { Gorduras totais }(\mathbf{g})}{\text { Presença adequada de arredondamento }}$ & - & - & - & - & 4 & 100 \\
\hline Valor zero & 24 & 39,3 & - & - & - & - \\
\hline $\begin{array}{l}\text { Inadequações } \\
\qquad \text { Ausência de teor de gorduras totais (g) }\end{array}$ & 37 & 60,6 & - & - & - & - \\
\hline$\frac{\text { Gorduras saturadas }(\mathbf{g})}{\text { Presença adequada de arredondamento }}$ & - & - & - & - & 4 & 100 \\
\hline Valor zero & 16 & 26,2 & - & - & - & - \\
\hline $\begin{array}{l}\text { Inadequações } \\
\qquad \text { Ausência de teor de gorduras saturadas (g) }\end{array}$ & 45 & 73,7 & - & - & - & - \\
\hline$\frac{\text { Fibras alimentares (g) }}{\text { Presença adequada de arredondamento }}$ & 5 & 8,2 & - & - & 4 & 100 \\
\hline Valor zero & 19 & 31,1 & - & - & - & - \\
\hline $\begin{array}{l}\text { Inadequações } \\
\quad \text { Ausência de teor de fibras alimentares (g) }\end{array}$ & 37 & 60,6 & - & - & - & - \\
\hline$\underline{\text { Sódio }(\mathbf{m g})}$ Presença adequada de arredondamento & 3 & 4,9 & - & - & 4 & 100 \\
\hline$\underline{\text { Valor zero }}$ & 20 & & - & - & - & - \\
\hline Ausência de teor de sódio (mg) & 37 & 60,6 & - & - & - & - \\
\hline Presença inadequada de arredondamento & 1 & 1,6 & - & - & - & - \\
\hline $\begin{array}{l}\text { Ferro }(\mathbf{m g}) \\
\text { Presença adequada de arredondamento }\end{array}$ & 2 & 3,3 & - & - & 4 & 100 \\
\hline Valor zero & 4 & 6,5 & - & - & - & - \\
\hline $\begin{array}{l}\text { Inadequações } \\
\text { Ausência de teor de ferro (mg) }\end{array}$ & 56 & 91,8 & - & - & - & - \\
\hline Presença inadequada de arredondamento & - & - & - & - & - & - \\
\hline$\underline{\text { Cálcio }(\mathbf{m g})}$ Presença adequada de arredondamento & 2 & 3,3 & - & - & 4 & 100 \\
\hline Valor zero & 3 & 4,9 & - & - & - & - \\
\hline Ausência de teor de cálcio (mg) & $\begin{array}{l}57 \\
56\end{array}$ & $\begin{array}{l}93,4 \\
91,8\end{array}$ & - & - & - & - \\
\hline Presença inadequada de arredondamento & 1 & 1,6 & - & - & - & - \\
\hline
\end{tabular}

$\mathrm{n}=$ Frequência absoluta encontrada; $\%$ = Percentual referente; nenhum produto da categoria sagu seco informou teores de gorduras totais e saturadas. Os teores de ferro e cálcio, quando informados, estiveram em desacordo com a Instrução Normativa $\mathrm{n}^{\circ} 75$, de 08 de outubro de 2020 da Agência Nacional de Vigilância Sanitária/ANVISA, uma vez que suas quantidades na porção indicada se enquadravam em "não significativos" mesmo quando a porção estava inadequada. Não foram informados teores de proteínas, gorduras totais e saturadas, fibras, sódio, cálcio e ferro nas misturas para sagu.

Fonte: Autores (2021). 
As informações apresentadas na tabela nutricional são referentes à porção indicada. Dessa forma, os conteúdos de valor energético e nutrientes precisam corresponder ao quantitativo da porção. A falta de informações obrigatórias lesa o consumidor e pode estar ferindo a função legal da rotulagem nutricional ao ocultar do consumidor as reais propriedades nutricionais do alimento (Resolução do Diretório Colegiado n.429, 2020).

De acordo com a Tabela 7, na maioria dos sagus secos não foi possível encontrar informações de valor energético, significando 57,4\% de inadequação para essa informação $(n=35)$. Quando indicado, os valores energéticos estiveram na faixa de $180 \mathrm{kcal}$ e $64 \mathrm{kcal}$, com média de $80 \mathrm{kcal} /$ porção indicada. Vale ressaltar que o valor mínimo encontrado não foi referente a menor porção descrita, reafirmando que não houve padronização entre os sagus de mesma categoria.

Referente às misturas para sagu, a categoria de valor energético obteve maioria adequada à legislação vigente (Instrução Normativa n.75/2020). Os 37,5\% de inadequações, neste caso, ocorreram por ausência de informação ou erro de porção, como já relatado. Independente disso, a faixa de valores encontrada esteve entre $76 \mathrm{kcal}$ e $115 \mathrm{kcal}$, com média de 103 $\mathrm{kcal} /$ porção indicada.

Analisando os teores de carboidratos nos sagus secos e misturas para sagu, repetiu-se a tendência de inadequação vista no valor energético, mantendo-se em 42,6\% $(\mathrm{n}=26)$ e $57,4 \%(\mathrm{n}=55)$ para os sagus secos e $65,5 \%(\mathrm{n}=10)$ e $37,5 \%(\mathrm{n}=6)$ para as misturas, respectivamente. Essa ausência de informações pode ser prejudicial ao consumidor, uma vez que produtos amiláceos são fontes de carboidratos, um nutriente essencial para a vida humana e ao mesmo tempo mantido sob controle em determinadas situações de saúde (Resolução do Diretório Colegiado n.429/2020; Instrução Normativa n.75/2020). Os carboidratos foram apresentados na faixa de $16 \mathrm{~g}$ e 43,53 g para sagus secos e $19 \mathrm{~g}$ e $28 \mathrm{~g}$ nas misturas para sagu, mantendo-se em todos os produtos como o nutriente em maior quantidade.

Salienta-se que nenhum dos produtos de mistura para sagu apresentou as informações de açúcares adicionados, mesmo sendo o açúcar o ingrediente de maior quantidade de acordo com as listas de ingredientes apresentadas. Por isso, não foi possível avaliar se seriam obrigados a apresentarem a nova rotulagem frontal (selos) no futuro, uma obrigatoriedade a partir de outubro de 2022 (Resolução do Diretório Colegiado n.429/2020; Instrução Normativa n.75/2020).

Ainda, foi encontrada a inesperada inadequação na quantidade de carboidratos, na qual a quantidade indicada foi superior à porção indicada. Esse resultado é algo impossível de acontecer, uma vez que a porção é a soma de todos os componentes nutricionais. Com isso, em 20 gramas de porção foram indicados $26 \mathrm{~g}$ de carboidratos, ocasionando interpretação incorreta de toda tabela.

O sagu de mandioca é um produto naturalmente baixo em teor de proteínas, gorduras, fibras, cálcio, sódio e ferro. Por isso, quando informados, não possuíram quantidades expressivas, caracterizando tanto o sagu seco como os demais produtos pesquisados exclusivamente fontes de energia e ricas em carboidratos. Dessa forma, os produtos analisados podem apresentar a declaração simplificada de nutrientes, de modo que os constituintes em questão são suprimidos da tabela nutricional e indicados imediatamente abaixo pela declaração "Não contém quantidades significativas de (acrescentar os nomes dos constituintes presentes em quantidades não significativas)". Todas as tabelas nutricionais das misturas para sagus utilizaram o modelo de declaração simplificada, seguindo as obrigatoriedades da legislação com 100\% de adequação (Resolução do Diretório Colegiado n.429/2020; Instrução Normativa n.75/2020).

Por outro lado, os sagus secos apresentaram inadequações nos requisitos de formatação da tabela nutricional em todos os parâmetros nutricionais avaliados (valor energético, carboidratos, proteínas, gorduras totais, gorduras saturadas, fibras alimentares, sódio, ferro e cálcio). Nesses produtos, ocorreu a declaração dos nutrientes obrigatórios em quantidades não significativas diretamente na tabela nutricional ao mesmo tempo em que ausentaram o texto de declaração simplificada exigida por lei já demonstrada acima e analisado na Tabela 7 (Instrução Normativa n.75/2020).

Referente aos valores apresentados de teor proteico, somente 1 marca de mistura para sagus indicou presença na 
porção de 50 gramas (porção esta anteriormente demonstrada como inadequada), e os sagus prontos para consumo com teores menores que 2,5\% por $100 \mathrm{~g}$ de produto (Instrução Normativa n. 75, 2020).

As fibras alimentares foram informadas em 5 produtos de sagus secos, variando entre $0,5 \mathrm{~g}(1,7 \%$ da porção) e $5 \mathrm{~g}$ (10\% da porção), não sendo apresentada na porção de 60 gramas. Já nas versões prontos para consumo, o teor de fibras não atingiu $1 \%$ da porção.

Os teores de sódio, cálcio e ferro foram os nutrientes menos frequentes e nutricionalmente quantificados, correspondendo abaixo de $1 \%$ da porção indicada para informação nutricional. Os valores diários de referência são respectivamente $2.000 \mathrm{mg}, 14 \mathrm{mg}$ e $1.000 \mathrm{mg}$. De fato, não precisariam ser apresentados, uma vez que o excesso de informações que não demonstram diferenciais nutricionais pode trazer equívocos a consumidores inexperientes (Instrução Normativa n.75/2020).

Nas Tabelas 8, 9 e 10 são encontrados os perfis de adequação e inadequação referentes às advertências sobre glúten e lactose em sagus secos, misturas para sagu e sagus prontos para consumo.

Tabela 8. Perfil de Informação de Glúten em sagus secos, misturas para sagus e sagus prontos para consumo disponíveis para comercialização no Brasil

\begin{tabular}{|c|c|c|c|c|c|c|}
\hline \multirow[t]{2}{*}{ Itens } & \multicolumn{2}{|c|}{ Sagus Secos } & \multicolumn{2}{|c|}{ Misturas para sagu } & \multicolumn{2}{|c|}{$\begin{array}{c}\text { Sagus prontos para } \\
\text { consumo }\end{array}$} \\
\hline & $\mathrm{n}$ & $\%$ & $\mathrm{n}$ & $\%$ & $\mathrm{n}$ & $\%$ \\
\hline Denominação de Glúten adequada & 14 & 23 & 7 & 43,7 & 4 & 100 \\
\hline Contém Glúten & 9 & 14,8 & 5 & 14,8 & - & - \\
\hline Não contém Glúten & 5 & 8,2 & 2 & 8,2 & 4 & 100 \\
\hline $\begin{array}{l}\text { Inadequações } \\
\qquad \text { Sem informações sobre glúten }\end{array}$ & 47 & 77 & 9 & 56,3 & - & - \\
\hline
\end{tabular}

$\mathrm{n}=$ Frequência absoluta encontrada; $\%=$ Percentual referente; naturalmente, o sagu de mandioca não contém ingredientes que tragam riscos a celíacos. Por outro lado, podem conter glúten por contaminação cruzada no compartilhamento de equipamentos, assim como as misturas para sagu ou sagus prontos para consumo.

Fonte: Autores (2021).

Tabela 9. Perfil de Informação de lactose em sagus secos e misturas para sagus disponíveis para comercialização no Brasil.

\begin{tabular}{|c|c|c|c|c|c|}
\hline \multirow{2}{*}{\multicolumn{2}{|c|}{ Itens }} & \multicolumn{2}{|c|}{ Sagus Secos } & \multicolumn{2}{|c|}{ Misturas para Sagus } \\
\hline & & $\mathrm{n}$ & $\%$ & $\mathrm{n}$ & $\%$ \\
\hline \multicolumn{2}{|l|}{ Denominação de Lactose adequada } & 59 & 96,6 & 16 & 100 \\
\hline \multirow{3}{*}{ Inadequações* } & & 2 & 3,3 & - & - \\
\hline & "Contém lactose" & - & - & - & - \\
\hline & "Não contém lactose" & 2 & 3,3 & - & - \\
\hline
\end{tabular}

$\mathrm{n}=$ Frequência absoluta encontrada; \% = Percentual referente;

*De acordo com a Resolução do Diretório Colegiado $\mathrm{n}^{\circ}$ 136, de 08 de fevereiro de 2007 da Agência Nacional de Vigilância Sanitária/ANVISA, "a declaração da presença de lactose é obrigatória nos alimentos [...] que contenham lactose em quantidade maior do que 100 (cem) miligramas por 100 (cem) gramas ou mililitros do alimento". Por isso, no caso dos sagus secos e misturas para sagus a adequação legal é não informar sobre lactose na embalagem.

Fonte: Autores (2021). 
Tabela 10. Perfil de Informação de lactose em sagus prontos para consumo disponíveis para comercialização no Brasil.

\begin{tabular}{|c|c|c|}
\hline \multirow[t]{2}{*}{ Itens } & \multicolumn{2}{|c|}{ Sagus prontos para consumo } \\
\hline & $\mathrm{n}$ & $\%$ \\
\hline \multicolumn{3}{|l|}{ Denominação adequada sobre Lactose } \\
\hline "Contém lactose" (nos produtos com lactose) & 3 & 75 \\
\hline Sem informações & 1 & 25 \\
\hline \multicolumn{3}{|l|}{ Inadequações* } \\
\hline "Não contém lactose" & - & - \\
\hline \multicolumn{3}{|c|}{$\begin{array}{l}\mathrm{n}=\text { Frequência absoluta encontrada; } \%=\text { Percentual referente; } \\
\text { *De acordo com a Resolução do Diretório Colegiado } \mathrm{n}^{\circ} 136 \text {, de } 08 \text { de fevereiro de } 2007 \text { da Agência Nacional de Vigilância } \\
\text { Sanitária/ANVISA, "a declaração da presença de lactose é obrigatória nos alimentos [...] que contenham lactose em quantidade maior do que } \\
100 \text { (cem) miligramas por } 100 \text { (cem) gramas ou mililitros do alimento", ainda não sendo obrigatória a declaração de ausência em alimentos } \\
\text { naturalmente sem lactose. } \\
\text { Fonte: Autores (2021). }\end{array}$} \\
\hline
\end{tabular}

$\mathrm{Na}$ alimentação brasileira, a presença de alimentos naturalmente contendo glúten é vasta e rotineira. As proteínas formadoras do glúten estão presentes em cereais como o trigo (Triticum spp.), o centeio (Secale cereale) e a cevada (Hordeum vulgare) ou em estirpes hibridizadas como o triticale, cereais estes com diversas aplicações na indústria de alimentos, como ingredientes em bebidas, pães, massas e bolos (Fenacelbra, 2010; Portaria n.1149, 2015). De acordo com a Lei 10.674/2003 todo e qualquer produto comercializado precisa informar sobre a presença ou ausência de glúten, mesmo que seja por compartilhamento de equipamentos ou área de produção.

Com os dados dispostos na Tabela 8, percebe-se que os sagus secos foram os que apresentaram mais inadequações (77\%), equivalendo a 47 produtos. Essa falha traz prejuízos ao consumidor que não conhece esse produto e não sabe que naturalmente os sagus são isentos de glúten e só poderiam conter glúten por contaminação cruzada por equipamentos compartilhados, uma vez que são constituídos de fécula de mandioca (Fenacelbra, 2010; Alves \& Santana, 2019).

A obrigatoriedade de declarar presença de lactose em alimentos tem um contexto diferente da compreendida na doença celíaca. A lactose é um carboidrato exclusivo de leites, na qual indivíduos intolerantes apresentam ausência ou redução da capacidade de metabolizar esse carboidrato à nível intestinal, podendo ser de origem congênita, primária ou secundária. Por ter alta prevalência na população brasileira, foi criada a obrigatoriedade condicional de informação em alimentos. Os produtos que contêm lactose acima de 100 miligramas na porção de 100 gramas ou 100 mililitros de alimento são obrigados a declarar a presença de lactose (Resolução do Diretório Colegiado, 2017a e 2017b; Batista, Assunção, Penaforte \& Japur, 2018).

Os sagus secos de mandioca não devem informar ausência de lactose, não havendo inadequação nessa categoria. Porém, as misturas para sagus e sagus prontos para consumo devem informar quando houver componentes com lactose. Para tal, de acordo com as Tabelas 9 e 10, nenhuma declaração de lactose foi encontrada nas versões mistura para sagu e 75\% dos sagus prontos para consumo alegaram ter lactose, o que é facilmente confirmado ao analisar as listas de ingredientes contendo leite em pó, soro de leite, leite condensado e creme de leite.

\subsection{Embalagens}

Apesar da Instrução Normativa n. 23/2020 do Ministério da Agricultura, Pecuária e abastecimento - MAPA determinar que as embalagens para alimentos sejam "apropriadamente limpos, atóxicos, que protejam o alimento e que não transmitam odores estranhos ao produto", não há imposição sobre o tipo de material a ser usado. Foi possível perceber uma expressiva comercialização em embalagens plásticas transparentes para as versões de sagus secos, tendo somente 1,6\% das marcas comercializando em papel Kraft $(n=2)$. Por outro lado, nas versões mistura para sagu o uso de papel cartão foi absoluto como embalagem secundária e as versões pronto para consumo utilizam embalagens plásticas aparentemente de polipropileno 
com vedação superior metálica.

Além de conservar e garantir a segurança do alimento, a embalagem pode ser desenvolvida para atrair, diferenciar e despertar a vontade de compra no consumidor (Rodrigues, Macedo, Drumond \& Castro, 2019). Todos os sagus prontos para consumo apresentavam ilustrações de seus ingredientes principais, como uvas, grãos de café e chocolates. Nas versões mistura para sagu, todos os produtos apresentavam painel principal ilustrações (ou fotos) das receitas prontas referentes aos seus sabores principais, como vinho, uvas e canela, morango e framboesas.

\subsection{Canais de Comunicação - Sites}

Os sites são ferramentas de comunicação direta com o consumidor final extremamente vantajosas na era digital. Ainda assim, 41 dos produtos não tinham site oficial, ou o sagu não se enquadrava na categoria correta ou mesmo só divulgava o painel principal da embalagem.

Os sagus foram encontrados nas categorias de sobremesas, doces e chocolates, produtos práticos, farináceos, grãos, cereais, festas, especiarias, "produto sem categoria" como também sagus e derivados da mandioca. Essa variedade de categorias pode confundir o consumidor e dificultar a busca do sagu de mandioca, uma vez que tudo acerca do produto precisa atender às expectativas de intenção de compra para ser adquirido (Rodrigues, Macedo, Drumond \& Castro, 2019).

Apenas 31,2\% ( $\mathrm{n}=2$, equivalendo a 5 produtos) das 6 marcas analisadas de mistura para sagu apresentavam o modo de preparo no site oficial. Tornando mais complicada a experiência do usuário com os diferentes sites, existiram equívocos quanto à declaração de origem do próprio produto: em 2 marcas distintas foram encontradas a explicação de origem do sagu de mandioca, informação equivocadamente errada ao explicitar que o sagu de mandioca vinha das palmeiras-sagu. Em contrapartida, 9 marcas $(11,3 \%)$ apresentaram informações corretas sobre a origem do sagu de mandioca.

Como atributos diferenciais, foram encontrados em 6 sites oficiais declarações sobre qualidade de processamento dos sagus ("produzido através das melhores práticas e processos"), apelo regional ("Nossa receita especial para uma sobremesa tradicional"), sugestão de receitas com frutas e leite, divulgação de receitas completas e modo de preparo, atributos sensoriais exclusivos ("seu sabor diferenciado e agradável é irresistível"). Por outro lado, foram encontrados apelos nutricionais equivocados nos sites e nas embalagens. Sobre os sagus secos, foi declarado no painel principal em 1 marca "Rico em carboidratos, proteínas, fibra alimentares, cálcio, ferro e vitaminas B1 e B2." Referente aos sagus prontos para consumo, como "o sagu traz maravilhas para a sua digestão, graças ao seu alto teor de fibra alimentar", "previne constipação intestinal e dor, e até reduz o risco de câncer de cólon", "remove o colesterol ruim, reduzindo o risco de ataques cardíacos e derrames, fortalece os ossos e promove o ganho de massa muscular", informações falsas e sem comprovação científica. Ainda, uma marca de sagu seco afirmou que havia "presença de milho transgênico", mesmo este não fazendo parte da composição do produto.

Em suma, há diversos pontos que podem ser melhorados para tornar a experiência do consumidor mais atraente e esclarecedora. Com isso, o mercado de sagus de mandioca no Brasil pode ter reflexos positivos de procura e consumo.

\section{Considerações Finais}

Esta pesquisa de mercado visou aprofundar o potencial de consumo e perfil de preço do sagu de mandioca, sendo o primeiro realizado visando exclusivamente o Brasil, tendo como eixo os dados apresentados pelas empresas ou compartilhado por revendedoras on-line.

Foi possível perceber que há uma quantidade relevante de sagus de mandioca, mesmo desconsiderando os fornecedores de sagu de mandioca a granel, indicando que o cenário atual tende a ser maior do que o analisado.

De acordo com os levantamentos, é possível adquirir sagu de mandioca em todas as regiões do país, principalmente 
nas regiões Sul e Sudeste. Mesmo assim, não há trabalhos que avaliem o padrão de comportamento de compra e consumo voltados para sagus e seus derivados. Em face desta limitação, entende-se que a população em geral não conhece o produto, criando uma barreira de mercado para quem nunca o consumiu. Seria interessante que as empresas produtoras de sagu de mandioca realizassem campanhas de marketing a fim de aproximar esse produto de potenciais clientes, uma vez que produtos estrangeiros influenciados pela cultura internacional têm ganhado espaço no mercado nacional.

Quanto às inadequações na rotulagem nutricional, não é possível para o consumidor ter informações confiáveis sobre valor energético, quantidades e valores diários de macronutrientes, vitaminas e minerais presentes em determinada porção do alimento, pois na comparação com produtos de mesma categoria há muitas incertezas para valores iguais, vide a relação porção e valor energético. Há inadequações quanto às características de identidade e qualidade exclusivas para sagus de mandioca, prejudicando sua expansão para grupos com alimentação restrita, como celíacos e indivíduos com sensibilidade ao glúten. Como perspectivas, as questões pertinentes à tabela de informação nutricional e rotulagem nutricional frontal de açúcares adicionados, p. ex., devem ser consideradas na renovação da embalagem ou reformulação de produtos como as misturas para sagu ou sagus prontos para consumo, no período de Vacatio legis das legislações de rotulagem nutricional.

Por fim, entende-se que pode haver influências favoráveis em utilizar as embalagens e os canais virtuais de comunicação para atrair a atenção e o desejo do consumidor em comprar produtos, incluindo os alimentícios. Por enquanto, foi percebido que não há diferenciais suficientes que atraiam marcas específicas, visto que há uma homogeneidade de embalagens, divulgação e formas de consumo de sagus.

Como perspectivas para trabalhos futuros, sugere-se uma pesquisa sobre o panorama de consumo de sagus de mandioca pela população brasileira, uma vez que as Pesquisas de Orçamento Familiar nacionais não trazem esse detalhamento e não há, até o momento, outras pesquisas de consumo com essa temática. Também é proposta a viabilização de informações mais acessíveis à população sobre composição, formas de consumo e novas receitas com sagu destinadas a diferentes públicos.

\section{Referências}

Alves, A. C. \& Santana, I. (2019). Pérolas à mesa: sobremesas à base de sagu de mandioca. UERJ.

Batista, R. A. B., Assunção, D. C. B., Penaforte, F. R. de O. \& Japur, C. C (2018). Lactose em alimentos industrializados: avaliação da disponibilidade da informação de quantidade. Ciência \& Saúde Coletiva, 23(12), 4119-4128.

Cascudo, L. C. (2011). História da Alimentação no Brasil (4a ed). Global.

Comissão Nacional de Normas e Padrões para Alimentos no 12 , de $2^{\text {a }}$ de julho (1978). Aprova as seguintes NORMAS TÉCNICAS ESPECIAIS, do Estado de São Paulo, revistas pela CNNPA, relativas a alimentos (e bebidas), para efeito em todo território brasileiro. Ministério da Saúde.

David, M. L. \& Guivant, J. S. (2020). Os Padrões de Identidade e Qualidade dos Alimentos: uma Análise de suas Transformações no Brasil. Mediações, 25(1), 247-264.

Estrela, C. (2018). Metodologia Científica: Ciência, Ensino, Pesquisa. Artes Médicas.

Pereira, A. S.; Shitsuka, D. M; Parreira, F. J. \& Shitsuka, R. (2018). Metodologia da pesquisa científica. UFSM.

Fenacelbra (2010). Guia orientador para celíacos. Artecor.

Food and Agriculture Organization of the United Nations (2021). FAOSTAT. http://www.fao.org/faostat/en/\#data/QC

Goodman, D. (2003). The quality 'turn' and alternative food practices: reflections and agenda. Journal of Rural Studies, (19,1), 1-7.

Instituto Brasileiro de Geografia e Estatísticas (2004). Pesquisa de Orçamentos Familiares 2002-2003. Brasília, DF, Brasil. https://www.ibge.gov.br/estatisticas/sociais/saude/9050-pesquisa-de-orcamentos-familiares.html?edicao=9051\&t=0-que-e

Instituto Brasileiro de Geografia e Estatísticas (2011). Pesquisa de Orçamentos Familiares 2008-2009. Brasília, DF, Brasil. https://www.ibge.gov.br/estatisticas/sociais/saude/9050-pesquisa-de-orcamentos-familiares.html?edicao=9051\&t=0-que-e 
Instituto Brasileiro de Geografia e Estatísticas (2020). Pesquisa de Orçamentos Familiares 2018-2019. Brasília, DF, Brasil. https://www.ibge.gov.br/estatisticas/sociais/saude/9050-pesquisa-de-orcamentos-familiares.html?edicao=9051\&t=o-que-e

Instrução Normativa n. 75, de 08 de outubro (2020). Estabelece os requisitos técnicos para declaração da rotulagem nutricional nos alimentos embalados. Agência Nacional de Vigilância Sanitária - ANVISA.

Instrução Normativa $n^{\circ}$ 23, de 14 de dezembro (2005). Aprova o Regulamento Técnico De Identidade E Qualidade Dos Produtos Amiláceos Derivados Da Raiz De Mandioca, conforme anexo. Ministério da Agricultura, Pecuária e Abastecimento - MAPA.

Lei $\mathrm{n}^{\circ} 10.674$, de 16 de maio (2003). Obriga a que os produtos alimentícios comercializados informem sobre a presença de glúten, como medida preventiva e de controle da doença celíaca. Subchefia de Assuntos Jurídicos da Agência Nacional de Vigilância Sanitária - ANVISA.

Decreto-lei n. 986, de 21 de outubro (1969). Inclui normas sobre alimentos. Presidência da República - Casa Civil - Subchefia para Assuntos Jurídicos.

Informe Técnico n. 26, de 14 de junho (2007). Padronizar as informações que devem constar no rótulo dos alimentos que contêm aroma em sua formulação para conferir, reforçar ou reconstituir o sabor ou ainda conferir sabor não específico. Agência Geral de Alimentos - GGALI/ Agência Nacional de Vigilância Sanitária - ANVISA.

Machado, S. S.; Santos, F. O., Albinati, F. L. \& Santos, L. P. R. (2006). Comportamento dos consumidores com relação à leitura de rótulo de produtos alimentícios. Alimentos e Nutrição, 17(1), 97-103.

Marins, B. R., Araújo, I. \& Jacob, S. (2014). Vigilância Sanitária e direito à comunicação: a rotulagem de alimentos como espaço de cidadania. Vigilância Sanitária em Debate, 2(4), 86-95.

Ministério da Saúde (2014). Guia Alimentar para a População Brasileira (2a ed). MS.

Peccini, R. (2010). Somos o que comemos: o terroir do sagu de vinho bordô In IV Seminário de Pesquisa em Turismo no Mercosul Saberes e Fazeres no turismo: interfaces, Anais. Caxias do Sul, RS, Brasil.

Portaria n. 1149, de 11 de novembro (2015). Aprova o Protocolo Clínico e Diretrizes Terapêuticas da Doença Celíaca. Ministério da Saúde.

Resolução do Diretório Colegiado no 135 , de 08 de fevereiro (2017a). Altera a Portaria SVS/MS no 29 , de 13 de janeiro de 1998 , que aprova o regulamento técnico referente a alimentos para fins especiais, para dispor sobre os alimentos para dietas com restrição de lactose. Agência Nacional de Vigilância Sanitária - ANVISA.

Resolução do Diretório Colegiado no 136, de 08 de fevereiro (2017b). Estabelece os requisitos para declaração obrigatória da presença de lactose nos rótulos dos alimentos. Agência Nacional de Vigilância Sanitária - ANVISA.

Resolução do Diretório Colegiado n ${ }^{\circ}$ 259, de 20 de setembro (2002). Aprova o Regulamento Técnico sobre Rotulagem de Alimentos Embalados. Agência Nacional de Vigilância Sanitária - ANVISA.

Resolução do Diretório Colegiado no 36, de 02 de julho (2015). Dispõe sobre os requisitos para rotulagem obrigatória dos principais alimentos que causam alergias alimentares. Agência Nacional de Vigilância Sanitária - ANVISA.

Resolução do Diretório Colegiado n 429, de 08 de outubro (2020). Dispõe sobre a rotulagem nutricional dos alimentos embalados. Agência Nacional de Vigilância Sanitária - ANVISA.

Rodrigues, L. C., Macedo, C. M., Drumond, \& Castro, M. C. (2019). Inovação das embalagens como fator estratégico: estudo de caso em uma indústria de alimentos. Braz. J. of Develop., 5 (8), 13515 - 13535. 